\title{
Liver Abscess: An Institutional Review at Gandaki Medical College Teaching Hospital
}

\author{
KC Hari B', Bhuju $S^{2}$, Dhakal RR2, Timilsina DS \\ 'Lecturer, ${ }^{2}$ Associate Professor, ${ }^{3}$ Professor \\ Department of Surgery, Charak Hospital, Gandaki Medical College \& Teaching Hospital, Pokhara, Nepal
}

\author{
Keywords \\ Liver abscess, Percutaneous drainage, \\ Pyogenic.
}

\section{Corresponding author \\ Dr. Hari Bahadur KC \\ Lecturer, Department of Surgery \\ Gandaki Medical College \& Teaching \\ Hospital, Pokhara, Nepal \\ E-mail: hari_kc7@yahoo.com}

\begin{abstract}
Background: Although liver abscess is a potentially life threatening disease, early diagnosis and prompt treatment has resulted good clinical outcome. The epidemiology and management of this condition have evolved over time.
\end{abstract}

Objective: To study our experience in clinical characteristics and management of liver abscess in a tertiary hospital over a period of three years.

Methods: The hospital records of all patients discharged with the diagnosis of liver abscess from September 2010 to March 2013 were reviewed. The demographics, clinical presentation, investigation tools, method of treatment and outcome were recorded and analyzed.

Results: Total of 17 patients of liver abscess were admitted during this period, of which, 13 were pyogenic and four amebic. The median age was 50 (7 - 75) years with male to female ratio of $1.42: 1$. Age group 40 - 60 years was most commonly affected. Single lesions were found in $11(64.7 \%)$ and multiple in six (35.3\%) patients. The most common presentation was fever and abdominal pain/tenderness. Jaundice was seen in five $(29.4 \%)$ patients and abnormal liver function test in $10(58.8 \%)$ patients. Commonest route of infection among pyogenic liver abscess were through biliary tree pathology (Five patients) and via portal venous system (Three patients). Pus and blood culture were positive in six (46.15\%) and four (30.76\%) patients respectively, and $E$. coli was the commonest pathogen isolated. Patients were treated with anti-microbial therapy and interventional radiology techniques: Nine patients with percutaneous needle aspiration, four with percutaneous drainage. Antibiotics alone were sufficient in three patients and open surgical drainage was required in one patient. There was one case of mortality where the abscess was associated with diabetes mellitus.

Conclusion: Liver abscess is a potentially life threatening disease and commonly associated with underlying gastrointestinal pathology. Adequate antibiotic coverage and image guided intervention is optimal first-line treatment with favorable outcome. 


\section{INTRODUCTION}

Liver abscess is a potentially life threatening disease which had high morbidity and mortality in past. Oschsner and DeBakey described the first largest study of liver abscess in their classic paper on pyogenic liver abscess in $1938^{1}$. Earlier it was the disease of the young people in their 20s - 30s largely in the setting of intra-abdominal infection, but at present it predominantly affects the elderly persons ${ }^{2,3}$. Recent studies have shown the biliary tree as the most common potential route of infection while no cause is seen in many cases ${ }^{4}$. The symptoms are largely non-specific and classical triad of fever, jaundice and right upper quadrant pain and tenderness are seen in less than $10 \%$ of population ${ }^{5}$.

Ultrasound and CT scan of abdomen are the mainstays of diagnostic modalities in liver abscess. The most common organisms involved are E coli and Klebsiella. Treatment of liver abscess has changed over the last two decades from surgical towards a minimal invasive approach, largely because of improved interventional radiologic techniques $\mathbf{6 , 7 , 8 , 9}$. Percutaneous drainage or intermittent needle aspiration in combination with systemic antibiotics are the current treatment of choice and surgical drainage is reserved for failure cases ${ }^{\mathbf{1 0}}$. In Nepal, no known large studies regarding management of liver abscess has been performed. We have tried to analyze the epidemiology, diagnostic modalities, predisposing factors and management options for liver abscess in our hospital over the period of three years.

\section{METHODS}

Hospital registers of the patients discharged with the diagnosis of liver abscess from September 2010 to March 2013 were reviewed. Case of liver abscess was defined as any patient having one or more filling defects in liver on abdominal Ultrasound or CT scan together with identification of pus or complete resolution of radiological abnormalities following antimicrobial therapy. The data regarding demographic profiles, duration of symptoms, clinical features, laboratory parameters, imaging findings, pus cultures, method of treatment were collected. Likewise predisposing factors, clinical course, any complications, duration of hospital stay and outcome were recorded. Liver abscess was considered secondary to biliary tract disease in patients with gall stones and/ or acute cholecystitis, or who had other documented biliary tract abnormality. It was considered secondary to portal spread when there was documented infection or abdominal pathology in the distribution of portal vein and was considered cryptogenic where no obvious extrahepatic source of infection was identified. Data were analyzed using SPSS version 17.0.

\section{RESULTS}

Fig 1: Age distribution of patients with liver abscess

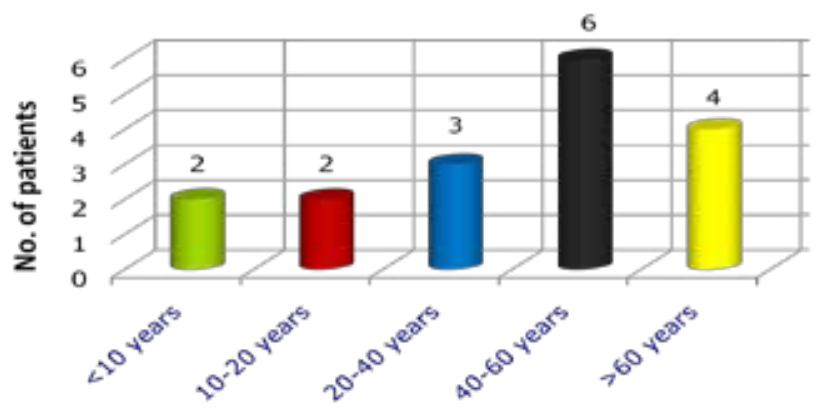

Fig 2: (a) Number of abscess; (b) Location of abscess

(a)

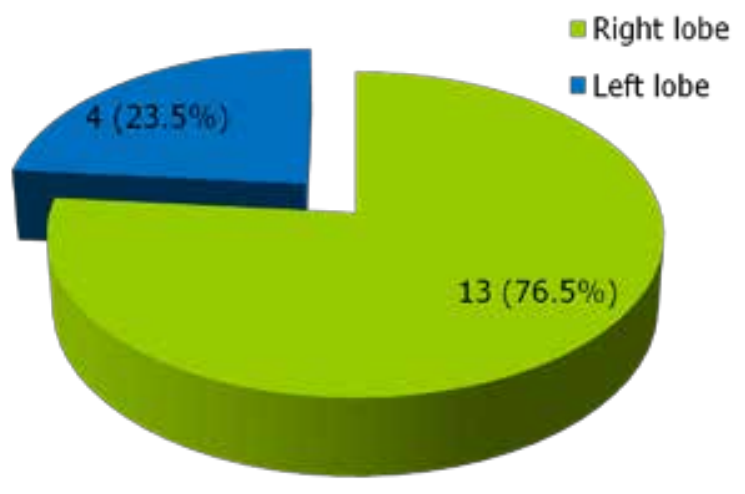

(b)

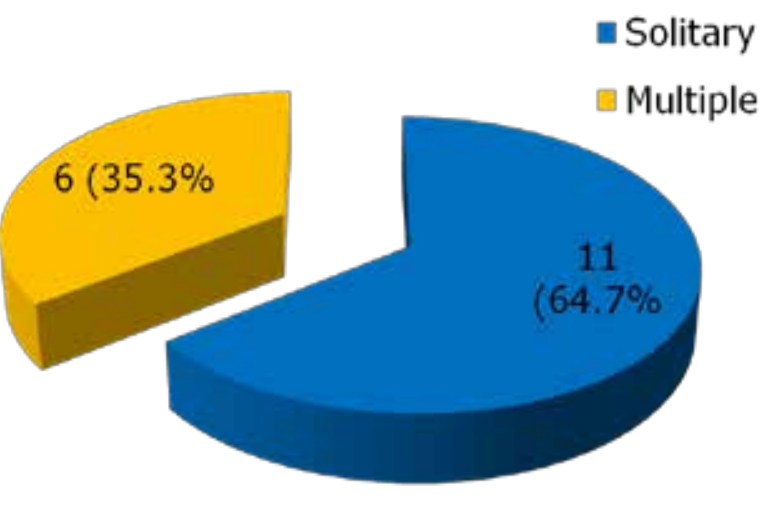

Table 1: Main complaints and clinical findings on admission

\begin{tabular}{lccc}
\hline Symptoms & $\begin{array}{c}\text { Number } \\
\text { (\%) }\end{array}$ & Signs & $\begin{array}{c}\text { Number } \\
\text { (\%) }\end{array}$ \\
\hline Abdominal pain & $16(94.1 \%)$ & Fever & $10(58.8 \%)$ \\
Fever & $11(64.7 \%)$ & $\begin{array}{c}\text { RUQ tender- } \\
\text { ness }\end{array}$ & $14(82.4 \%)$ \\
Nausea /vomiting & $5(29.4 \%)$ & $\begin{array}{c}\text { Jaundice } \\
\text { Weight loss }\end{array}$ & $5(29.4 \%)$ \\
Night sweat & $7(45.3 \%)$ & Chest signs & $4(23.5 \%)$ \\
Diarrhea & $4(23.5 \%)$ & Hepatomegaly & $7(41.2 \%)$ \\
Jaundice & $4(23.5 \%)$ & & \\
\hline
\end{tabular}


Table 2: Hematological and biochemical parameters on the day of admission

\begin{tabular}{|c|c|c|c|}
\hline Tests & Mean (range) & $\begin{array}{c}\text { Normal } \\
\text { value }\end{array}$ & $\begin{array}{c}\text { Abnormal } \\
\text { test result } \\
\text { n (\%) }\end{array}$ \\
\hline $\begin{array}{l}\text { White cell count } \\
\left(/ \mathrm{mm}^{3}\right)\end{array}$ & $\begin{array}{c}15000 \\
(6600-25000)\end{array}$ & $\begin{array}{l}4000- \\
11000\end{array}$ & $15(88.2 \%)$ \\
\hline Neutrophil (\%) & $\begin{array}{c}75 \% \\
(49-85)\end{array}$ & $50-70$ & $14(82.3 \%)$ \\
\hline $\begin{array}{l}\text { Hemoglobin } \\
\text { (gm/dl) }\end{array}$ & $\begin{array}{c}14.2 \\
(12.4-16.5)\end{array}$ & $12.2-16.4$ & \\
\hline Bilirubin (mg/dl) & $\begin{array}{c}1.1 \\
(0.8-4.6)\end{array}$ & $0.3-1.0$ & $5(29.4 \%)$ \\
\hline AST (IU/L) & $\begin{array}{c}36 \\
(20-95)\end{array}$ & $10-34$ & $7(41.25)$ \\
\hline ALT (IU/L) & $\begin{array}{c}37 \\
(21-110)\end{array}$ & $7-33$ & $9(52.9 \%)$ \\
\hline ALP (IU/L) & $\begin{array}{c}156 \\
(93-540)\end{array}$ & $20-140$ & $9(52.9 \%)$ \\
\hline LFT & & & $10(58.8 \%)$ \\
\hline
\end{tabular}

$\overline{\text { ALT, }}$ alanine aminotransferase; AST, aspartate aminotransferase; ALP, alkaline phosphatase; LFT, liver function test

Table 3: Potential underlying pathology among patients with pyogenic liver abscess

\begin{tabular}{ccc}
\hline Causes & Patient Number & Percentage(\%) \\
\hline Biliary & 5 & $38.46 \%$ \\
Portal & 4 & $30.76 \%$ \\
$\begin{array}{c}\text { Crypto- } \\
\text { genic }\end{array}$ & 4 & $30.76 \%$ \\
\hline
\end{tabular}

Fig 3: Bacterial isolates from pus and blood of patients with pyogenic liver abscess

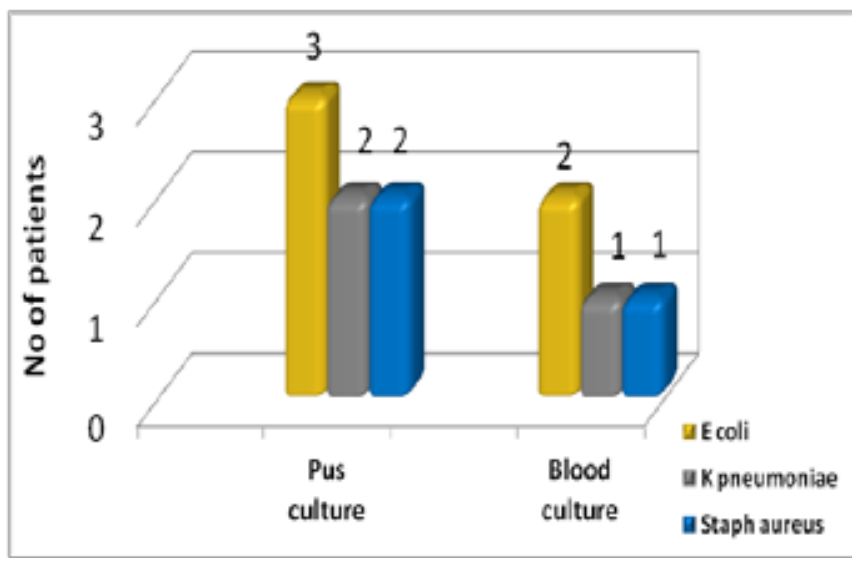

Table 4: Different modalities of treatment employed

\begin{tabular}{lccl}
\hline \multicolumn{1}{c}{ Treatment method } & No. & \multicolumn{1}{c}{$\%$} & Outcome \\
\hline Antibiotic alone & 3 & $17.6 \%$ & \\
$\begin{array}{l}\text { Antibiotics and } \\
\text { percutaneous aspiration }\end{array}$ & 9 & $52.9 \%$ & $\begin{array}{l}\text { Multiple aspirations } \\
\text { required }\end{array}$ \\
$\begin{array}{l}\text { Antibiotics an } \\
\text { percutaneous drain }\end{array}$ & 4 & $23.5 \%$ & \\
\begin{tabular}{l} 
Surgical drainage \\
\hline
\end{tabular} & 1 & $5.9 \%$ & Death \\
\hline
\end{tabular}

Fig 4: Number of aspiration performed in patient treated with percutaneous aspiration

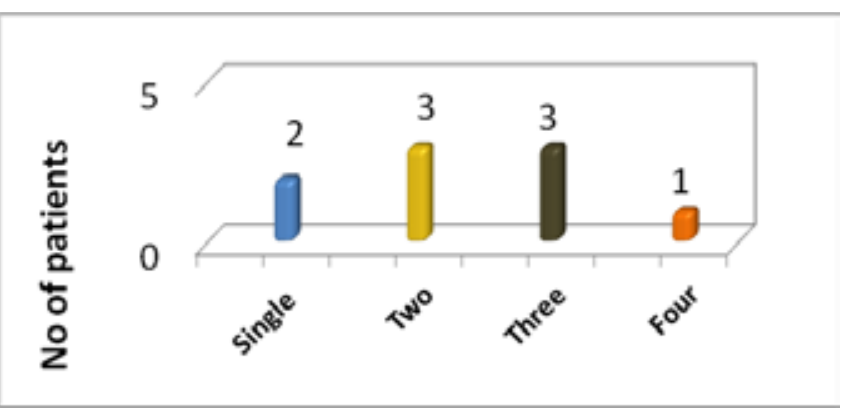

Total of 17 patients of liver abscess were admitted during this period, of which, 13 were pyogenic and four amebic abscesses. The median age was $50(7-75)$ years with male to female ratio of $1.42: 1$. Age group $40-60$ years was most commonly affected (Fig 1). Single lesions were found in 11 (64.7\%) and multiple in six (35.3\%) patients. In 13 patients $(76.5 \%)$, the abscess was on right lobe and in four (23.5\%) patients on left lobe (Fig 2). Average duration of symptoms before presenting to hospital was $19.18 \pm 9.1(10-45)$ days. The most common symptoms and signs were fever (64.7\%) and abdominal pain/tenderness (94.1\%). Clinically evident jaundice was seen in 5 (29.4\%) patients (Table1). The results of routine hematological and biochemical tests are shown on Table 2. Most of the patients had leukocytosis (88.2\%) and neutrophilia (82.3\%) and 10 (58.8\%) patients had abnormal liver function tests. Ultrasound was the initial imaging tool in all patients and had the accuracy of $88 \%$. Abdominal CT scan was performed in 12 patients (70.6\%).

Four patients had positive Entamoeba histolytica serology, hence labeled as amebic liver abscess. Of them three had single lesions; one had multiple lesions and in three patients, abscesses were on right lobe of liver. All of them were treated with antibiotics which included metronidazole. Of them, two received only antibiotics while two patients underwent percutaneous aspiration as well.

Potential underlying pathology was found in nine out of 13 (69.23\%) patients with pyogenic liver abscess. Among 
them five patients had biliary tree pathology and spread of infection via portal venous system was suspected in four patients, while four patients were regarded as cryptogenic because no definitive causes were found in them (Table 3). Pus and blood culture were positive in six $(46.15 \%)$ and four (30.76\%) patients respectively, and $E$. coli was the commonest pathogen isolated (Fig 3).

Various modalities of treatment were utilized for the patients (Table 4). Among the pyogenic abscess group, only antibiotics were sufficient for three patients. Percutaneous aspiration along with antibiotic coverage was the treatment in nine patients, and multiple aspirations were required for most of them (Fig 4). Percutaneous drainage and adequate antibiotics was performed in four patients. Choice of antibiotics was according to the protocol, empirically the broad spectrum antibiotics to cover all possible common microbes, and it was changed according to the culture sensitivity report once available. Intravenous ceftriaxone and metronidazole were given for 10 to 14 days followed by oral ciprofloxacin and metronidazole for variable periods depending on the response.

\section{DISCUSSION}

Liver abscess, particularly the pyogenic, is more prevalent in elderly population as compared to the higher incidence among younger population in the past. In a study by Mohsen et al, $77 \%$ of patients were above 50 years $^{9}$ and in our study too, age group 40 - 60 years was the most prevalent one. There was male preponderance which is in accordance with other studies ${ }^{9.10,11}$.

Various predisposing factors are involved in liver abscess, the commonest being portal venous spread, biliary tree pathology and cryptogenic etiology. This study shows the biliary tree pathology as the most common underlying factor followed by spread of infection through portal venous system (38\% vs $23 \%$ ) and this finding is supported by studies by Bertel $e t a l^{12}$, Cohen $e t a l^{13}$, Chan et $a l^{11}$ while is opposed by Ochsner et al ${ }^{1}$, Perera et $a l^{2}$ and Mohsen et $a l^{9}$ where portal venous spread was most common. One patient had history of liver trauma six months back. Only one patient had diabetes mellitus; however higher incidence was reported in other studies. There is high percentage of cryptogenic cases (30\%) which can be due to inadequate evaluation for the cause and warrants more vigorous search for the underlying cause. Factors contributing for portal venous spread are colonic diseases like diverticulitis, inflammatory bowel disease, carcinoma; gastric condition like atrophic gastritis resulting in change in the bowel bacterial flora ${ }^{14}$; and immunocompromised conditions like diabetes, steroid use etc. Half of the pyogenic liver abscesses are multicentric and three-fourth are located on right lobe. In this study, $77 \%$ lesions are located on right side which is in accordance with similar results from Alvarez et $a l^{15}$ and Wong et $a l^{16}$. Regarding multicentricity, one third of patients in this study had multiple lesions, as also reported by other studies ${ }^{9,11}$.

The clinical features of liver abscess are non-specific. The most common features are fever and abdominal pain. Abdominal pain and tenderness was found in $94.1 \%$ of patients and was mostly right upper quadrant while fever was found in $64.7 \%$ of cases. Other non specific symptoms like nausea/vomiting, weight loss, night sweat, chest pain, diarrhea were found in about one third of patients. Clinical evidence of jaundice was seen in five $(29.4 \%)$ cases while a lower incidence of $14 \%$ was seen in study by Mohsen et $a l^{9}$. Most cases presented late in the hospital with average duration of 19 days after symptoms started.

Abdominal ultrasound is the most commonly used diagnostic tool with sensitivity of $90 \%{ }^{9}$. It is the initial imaging tool and the lesion appears as round to oval mass which is hypoechoic than liver parenchyma. It was performed in all patients and the accuracy in this series is $88 \%$ while CT scan was positive in all who had undergone this test. CT scan is highly sensitive with (95 - 100\%) and can pick up small abscess and multiple abscesses which may be missed by Ultrasound. They appear as hypodense space occupying lesion with enhanced wall. Both CT and ultrasound are useful in diagnosing other intra-abdominal pathology, such as biliary disease (ultrasound) or inflammatory disorders like appendicitis or diverticulitis (CT).

The bacteriological analysis in our series revealed that $E$. coli was the most common pathogen isolated, which is in accordance with the many studies reported from Western countries $^{9,17}$, however higher incidence of Klebsiella pneumoniae was reported in studies from Taiwan ${ }^{18,19}$. In this study pus culture was positive in $46 \%$ cases and blood culture only in $30 \%$ patients which is quite low as compared to other studies where pus and blood culture is positive in $75 \%$ and $50 \%$ cases. This low rate of isolation of microbes in culture can be attributed to many factors like poor quality of lab, improper technique of sample collection and transport, non-availability of anaerobic culture, many patients already had antibiotics etc.

When the diagnosis of pyogenic hepatic abscess is suspected, broad-spectrum IV antibiotics are started immediately to control ongoing bacteremia and its associated complications. Blood cultures and cultures of the abscess from aspiration are sent for aerobic and anaerobic cultures. The combination of ceftriaxone and metronidazole was used intravenously for 10-14 days followed by oral agents (ciprofloxacin and metronidazole). 
The management of liver abscess has evolved over time. Before the use of antibiotics and surgical drainage procedures, liver abscess was fatal disease. Open surgical drainage was gradually started and, with the addition of antibiotics, was the sole treatment for hepatic abscess until the 1980s. However, since then less invasive percutaneous drainage techniques have been employed with good results and open surgical drainage is reserved for failure cases only, 20,21. Indications of open surgical drainage at present time are failure of percutaneous drainage, large abscess $>10 \mathrm{~cm}$, requiring surgical treatment for other pathology eg. appendicitis, proximity to vital structures etc.

Percutaneous drainage procedures for pyogenic hepatic abscesses were first reported in 1953 but did not gain widespread acceptance until the development of high-quality imaging techniques and expertise in interventional radiologic techniques after 1980s. It has become the treatment of choice for liver abscess during last 20 years with success rates ranging from 69\% to $90 \%{ }^{10,22,23}$. The advantages to catheter drainage are the simplicity of treatment, avoidance of general anesthesia and a laparotomy while relative contraindications include the presence of ascites, coagulopathy, or proximity to vital structures. In this study, percutaneous ultrasound guided drainage was used in four patients.

Nine patients in our study were subjected to percutaneous needle aspiration. This technique has become popular in recent time. The abscess is aspirated under ultrasound guidance with wide bore needle and usually multiple aspiration is required. In a study by $\mathrm{Yu}$ CH in 2004, 64 patients were randomized into two groups: Continuous catheter drainage and intermittent needle aspiration. The outcome was similar in terms of treatment success rate, hospital stay, antibiotic duration, and mortality. Two third patients required multiple aspirations; $40 \%$ required two aspirations, and $20 \%$ required three aspirations ${ }^{\mathbf{1 0}}$.

There are some reports of treatment of liver abscess with antibiotics alone; however its role as standard treatment is controversial. Variable success rate as high as $79 \%{ }^{24}$ (Herbert DA et al 1982) and as low as $7 \%{ }^{7}$ (McCorkell S 1985) has been reported. In a study by Mohsen et al, success of antibiotics alone was 58.4\% (Seven out of 12 patients) ${ }^{9}$. Since most patients have had a diagnostic aspiration and thus at least a partial drainage in these cases. However, some series have shown very high mortality rate with antibiotics alone without any drainage procedures $(59 \%-100 \%)^{25}$. In present study, three patients were treated with antibiotics alone.

\section{CONCLUSIONS}

Liver abscess is a potentially life threatening disease, the epidemiology and management of which have changed over time. The common associated pathology is the underlying gastrointestinal disorders like biliary tree and portal tract diseases. The clinical presentation is variable with fever and abdominal pain being the most common findings. Image guided percutaneous aspiration or drainage along with adequate antibiotics is the first line treatment of liver abscess at present time.

\section{REFERENCES}

1. Ochsner A, De Bakey M, Murrey S. Pyogenic liver abscess II: An analysis of forty-seven cases with review of the literature. Am J Surg. 1938; 40: 292-319.

2. Perera MR, Kirk A, Noone P. Presentation, diagnosis and management of liver abscess. Lancet. 1980; 2: 629-32.

3. Branum DD, Tyson GS, Branum MA, Meyers WC. Hepatic abscess: Changes in etiology, diagnosis, and management. Ann Surg. 1990; 121: 655-62.

4. Man KC, Tat SF, Edward CSL et al. Pyogenic liver abscess: An audit of experience over the past decade. Arch Surg. 1996; 131: 148-52.

5. D’Angelica M, Fong Y. The Liver. In: Townsend CM et al editors. Sabiston Textbook of Surgery. 18th ed. Philadelphia: Elsevier; 2008. p. 1489.

6. Herbert DA, Fogel DA, Rothman J, Wilson S, Simmons F, Ruskin J. Pyogenic liver abscesses: Successful nonsurgical therapy. Lancet. 1982; 1: 134-6.

7. McCorkell SJ, Niles NL. Pyogenic liver abscesses: Another look at medical management. Lancet. 1985; 1: 803- 6 .

8. Rajak CL, Gupta S, Jain S, Chawla Y, Gulati M, Suri S. Percutaneous treatment of liver abscesses: Needle aspiration versus catheter drainage. Am J Roentgenol. 1998; 170: 1035-9.

9. Mohsen AH, Green ST, Read RC, McKendrick MW. Liver abscess in adults: ten years experience in a UK centre. Q J Med. 2002; 95: 797-802.

10. Yu Simon CH, Ho Simon SM, Lau WY, Yeung Deacons TK, Yuen Edmund HY, Lee Paul SF et al. Treatment of pyogenic liver abscess: Prospective randomized comparison of catheter drainage and needle aspiration. Hepatology. 2004; 39: 932-8.

11. Chan KS, Chen CM, Cheng KC, Hou CC, Lin HJ and Yu WL. Pyogenic liver abscess: A retrospective analysis of 107 patients during a 3-Year Period. Jpn J Infect Dis. 2005; 58: 366-8.

12. Bertel CK, Van Heeden JA, Sheedy PF II. Treatment of pyogenic hepatic abscesses: Surgical vs PCD. Arch 
Surg. 1986; 121: 554-8.

13. Cohen JL, Martin MF, Rossi LR, Schoetz DJ. Liver abscess: The need for complete gastrointestinal evaluation. Arch Surg. 1989; 124: 561-4.

14. Krasinski SD, Russell RM, Samloff IM et al. Fundic atrophic gastritis in an elderly population: Effect on hemoglobin and several serum nutritional indicators. J Am Geriatr Soc. 1986; 34: 800-6.

15. Alvarez JA, Gonzalez JJ, Baldonedo RF, Sanz L and Carreno G. Single and multiple pyogenic liver abscesses: etiology, clinical course, and outcome. Dig Surg. 2001; 18: 283-8.

16. Wong WM, Wong BC, Hui CK, Ng M, Lai KC, Tso WK, Lam SK, Lai CL. Pyogenic liver abscess: Retrospective analysis of 80 cases over a 10-year period. $J$ Gastroentero Hepatol. 2002; 17: 1001-7.

17. Alvarez JA, Gonzalez JJ, Baldonedo RF, Sanz L, Carreno G, Junco A Rodriguez JI et al. Clinical course, treatment, and multivariate analysis of risk factors for pyogenic liver abscess. Am J Surg. 2001; 181: 177-86.

18. Chou FF, Sheen-Chen SM, Chen YS and Chen MC. Single and multiple pyogenic liver abscesses: Clinical course, etiology and results of treatment. World J Surg. 1997; 21: 384-8.
19. Cheng HP, Chang FY, Fung CP, and Siu LK. Klebsiella pneumoniae liver abscess in Taiwan is not caused by a clonal spread strain. J Microbiol Immunol Infect. 2002; 35: 85-8.

20. Satiani B, Davidson ED. Hepatic abscesses: Improvement in mortality with early diagnosis and treatment. Am J Surg. 1978; 135: 647-50.

21. Pitt HA, Zuidema GD. Factors influencing mortality in the treatment of pyogenic hepatic abscess. Surg Gynecol Obstet. 1975; 140: 228-34.

22. Kaplan GG, Gregson DB, Laupland KB: Populationbased study of the epidemiology of and the risk factors for pyogenic liver abscess. Clin Gastroenterol Hepatol. 2004; 2: 1032-8.

23. Johannsen EC, Sifri CD, Madoff LC. Infections of the liver: Pyogenic liver abscess. Infect Dis Clin N Am. 2000; 14: 547-63.

24. Herbert DA, Fogel DA, Rothman J et al. Pyogenic liver abscesses: Successful non-surgical therapy. Lancet. 1982; 1: 134-6.

25. Pope IM, Poston GJ: Pyogenic liver abscess. In: Blumgart LH, Fong Y, ed. Surgery of the Liver and Biliary Tract, London: WB Saunders; 2000: 1135-45. 